\title{
Erratum
}

\section{Increased serum levels of serine enantiomers in patients with depression - ERRATUM}

\author{
Kenji Hashimoto, Taisuke Yoshida, Masatomo Ishikawa, Yuko Fujita, Tomihisa Niitsu, \\ Michiko Nakazato, Hiroyuki Watanabe, Tsuyoshi Sasaki, Akihiro Shiina, Tasuku Hashimoto, \\ Nobuhisa Kanahara, Tadashi Hasegawa, Masayo Enohara, Atsushi Kimura, Masaomi lyo
}

doi: 10.1017/neu.2015.59. Published by Cambridge University Press, October 2015.

There was an error in Table 2 which presented the values as ten times lower than the exact concentration. Please see the corrected Table 2 below.

The authors apologize for this error.

Table 2. Serum levels of amino acids and the ratio of amino acids in control subjects and major depressive disorder patients

\begin{tabular}{lccr}
\hline & Controls $(n=78)$ & Patients $(n=70)$ & $p$ values \\
\hline Amino acids & & & \\
D-Serine $(\mu \mathrm{M})$ & $0.844 \pm 0.029$ & $1.099 \pm 0.036$ & $<0.001$ \\
L-Serine $(\mu \mathrm{M})$ & $92.07 \pm 3.33$ & $110.74 \pm 2.80$ & $<0.001$ \\
Glycine $(\mu \mathrm{M})$ & $254.33 \pm 9.03$ & $240.83 \pm 8.76$ & 0.287 \\
Glutamate $(\mu \mathrm{M})$ & $45.67 \pm 2.30$ & $47.83 \pm 2.68$ & 0.539 \\
Glutamine $(\mu \mathrm{M})$ & $533.89 \pm 9.94$ & $548.20 \pm 10.09$ & 0.315 \\
Ratio & & & \\
L-Serine/Glycine & $0.386 \pm 0.146$ & $0.483 \pm 0.125$ & $<0.001$ \\
D-Serine/L-Serine & $0.0094 \pm 0.0023$ & $0.0102 \pm 0.0030$ & 0.078 \\
Glutamine/Glutamate & $13.61 \pm 5.29$ & $14.11 \pm 7.00$ & 0.623 \\
\hline
\end{tabular}

The data show the mean \pm SD. The data were analysed by Student's $t$-test.

\section{Reference}

Hashimoto K, Yoshida T, Ishikawa M, Fujita Y, Nitsu T, Nakazato M, Watanabe H, Sasaki T, Shina A, Hashimoto T, Kanahara N, Hasegawa T, Enohara M, Kimura A, Iyo M. Increased serum levels of serine enantiomers in patients with depression. Acta Neuropsychiatrica, available on CJO2015. doi:10.1017/neu.2015.59. 